\title{
Malignant gliomas: old and new systemic treatment approaches
}

\author{
Tanja Mesti ${ }^{1}$, Janja Ocvirk ${ }^{1,2}$ \\ ${ }^{1}$ Department of Medical Oncology, Institute of Oncology Ljubljana, Ljubljana, Slovenia \\ ${ }^{2}$ Faculty of Medicine, University of Ljubljana, Ljubljana, Slovenia \\ Radiol Oncol 2016; 50(2): 129-138.
}

Received 30 June 2014

Accepted 29 September 2014

Correspondence to: Asisst. Prof. Janja Ocvirk, M.D., Ph.D., Institute of Oncology Ljubljana, Zaloška 2, SI-1000 Ljubljana, Slovenia. Phone: +386 15879 220; Fax: +386 15879 305; E-mail: jocvirk@onko-i.si

Disclosure: No potential conflicts of interest were disclosed.

Background. Malignant (high-grade) gliomas are rapidly progressive brain tumours with very high morbidity and mortality. Until recently, treatment options for patients with malignant gliomas were limited and mainly the same for all subtypes of malignant gliomas. The treatment included surgery and radiotherapy. Chemotherapy used as an adjuvant treatment or at recurrence had a marginal role.

Conclusions. Nowadays, the treatment of malignant gliomas requires a multidisciplinary approach. The treatment includes surgery, radiotherapy and chemotherapy. The chosen approach is more complex and individually adjusted. By that, the effect on the survival and quality of life is notable higher.

Key words: malignant gliomas; systemic treatment; multidisciplinary; survival; quality of life

\section{Introduction}

Malignant (high-grade) gliomas are rapidly progressive brain tumors comprising of anaplastic oligodendroglioma, anaplastic astrocytoma, mixed anaplastic oligoastrocytoma (all grade III, World Health Organization [WHO]) and glioblastoma (grade IV, WHO). ${ }^{1}$

The incidence of malignant gliomas is approximately 5/100,000. Malignant gliomas constitute $35-45 \%$ of primary brain tumors. Glioblastomas account for approximately 60 to $70 \%$ of malignant gliomas, while anaplastic astrocytomas represent 10 to $15 \%$, and anaplastic oligodendrogliomas and anaplastic oligoastrocytomas $10 \%$ of malignant gliomas. ${ }^{1-3}$ The incidence of these tumors has increased slightly over past two decades, especially in the elderly. The peak incidence is in the fifth and sixth decade of life. The median age of patients at the time of diagnosis in the case of glioblastoma is 64 years and in the case of anaplastic gliomas 45 years. Malignant gliomas are $40 \%$ more frequent in men than in women and twice more frequent in white population than in black one. ${ }^{2,4,5}$
In Slovenia from 1991 till 2005, a total of 1636 patients (878 males and 758 females) were diagnosed with brain cancer. Since 2001 till 2005 the microscopical verification was performed in $83 \%$ of cases: $82 \%$ were gliomas, of which two thirds were glioblastoma, $14 \%$ astrocytoma and 10\% oligodendroglioma. Approximately $60 \%$ of the patients were diagnosed at age between 50 to 74 years, and $25 \%$ at age between 20 to 49 years. ${ }^{6}$

The only established environmental risk factor identified for the majority of malignant gliomas is exposure to ionizing radiation. ${ }^{4}$ There is suggestive evidence with unclear importance of and association of immunologic factors in the development of malignant gliomas, as patients with atopy have a reduced risk of gliomas ${ }^{7}$ and patients with glioblastoma with elevated IgE levels appear to live longer than those with normal levels. ${ }^{8}$ Also gene polymorphisms that affect detoxification, DNA repair, and cell cycle regulation have also been implicated in the development of gliomas. ${ }^{4}$

Few genetic syndromes are associated with the increased risk for malignant gliomas. ${ }^{9}$ Five percent of patients with malignant gliomas have a family 
history of gliomas, such as neurofibromatosis 1 and 2, retinoblastoma, the Li-Fraumeni syndrome, the Turcot's syndrome (the inherited mutations are presented in the Table 1). ${ }^{10}$

\section{Molecular pathology}

The malignant gliomas arise from neural progenitor cells. Malignant gliomas contain multipotent tumour stem cells that are responsible for populating and repopulating the tumours. ${ }^{11,12}$

Classical cytogenetic and array - based comparative genomic hybridization studies of gliomas have identified copy number changes (deletions, amplification, gains) in several regions; deletions

TABLE 1. Inherited mutation present in patients with malignant gliomas

\begin{tabular}{|c|c|c|}
\hline Syndrome & Gene name & $\begin{array}{l}\text { Chromosomal } \\
\text { location }\end{array}$ \\
\hline Neurofibromatosis 1 & Neurofibromin 1 (NF1) & $17 q 11$ \\
\hline Neurofibromatosis 2 & Neurofibromin 2 (NF2) & $22 q 12$ \\
\hline Tuberous sclerosis & $\begin{array}{l}\text { Tuberous sclerosis } 1 \text { (TSC1) } \\
\text { Tuberous sclerosis } 2 \text { (TSC2) }\end{array}$ & $\begin{array}{l}9 q 34 \\
16 p 13\end{array}$ \\
\hline Retinoblastoma & Retinoblastoma 1 (RB 1) & $13 q 14$ \\
\hline $\begin{array}{l}\text { Li-Fraumeni } \\
\text { syndrome }\end{array}$ & Tumor suppressor p53 (TP53) & 17p13 \\
\hline $\begin{array}{l}\text { Turcot's syndrome } \\
\text { and multiple } \\
\text { hamartoma }\end{array}$ & $\begin{array}{l}\text { Adenomatous polyposis coli (APC) } \\
\text { DNA mismatch repair genes: } \\
\text { Recombinant human MutL } \\
\text { homolog-1 (hMLH2) } \\
\text { MutS homolog } 2 \text { (hMSH2) } \\
\text { Mismatch repair endonuclease (PMS2) } \\
\text { Phosphatase and tensin homolog (PTEN) }\end{array}$ & $\begin{array}{l}3 p 21.3 \\
2 p 22-21 \\
7 p 22 \\
10 q 23.3\end{array}$ \\
\hline
\end{tabular}

\section{Differentiated astrocytes or precursors cells}

p53 mutation (>65 percent) PDGF-A, PDGFR- $\alpha$ overexpression (60 percent)

\section{Low grade astrocytoma \\ LOH 19q (50 percent) \\ $\mathrm{RB}$ alteration (25 percent) \\ $\checkmark$}

\begin{tabular}{|l|}
\hline \multicolumn{2}{|l|}{ Anaplastic astrocytoma } \\
\hline LOH $10 q$ \\
PTEN mutation (5 percent) \\
DCC loss of expression (50 percent) \\
PDGFR- $\alpha$ amplification (<10 percent)
\end{tabular}

Secondary glioblastoma

FIGURE 1. Development of primary and secondary glioblastoma

$\mathrm{DCC}=$ deleted in colon cancer gene; $\mathrm{LOH}=$ loss of heterozygosity; PDGF = platelet-derived growth factor; $\mathrm{PDGFR}=$ platelet-derived growth factor receptor; $\mathrm{RB}=$ retinoblastoma gene and loss of heterozygosity in tumours might point to genes involved in tumour initiation or progression (e.g. oncogenes). The chromosomal alterations that are mostly observed in gliomas are presented in Table $2 .{ }^{10}$

The transition from low grade to anaplastic astrocytoma is associated with inactivation of tumour suppressor genes on chromosomes 9p, $12 q$ and $19 q$. Loss of chromosome $13 q$, which includes the retinoblastoma (RB) gene focus, occurs in approximately $30 \%$ of higher-grade astrocytic tumours. Two-thirds of malignant astrocytomas and glioblastomas have homozygous deletions of the region of chromosome $9 p$ that includes the cyclin-dependent kinase inhibitor 2A (CDKN2A) and CDKN2B genes. In general, RB, CDKN2A and cyclin- dependent kinase (CDK)4 gene alterations are mutually exclusive in glioblastomas. ${ }^{13}$ Malignant progression to glioblastoma is also associated with inactivation of the phosphatase and tensin homolog (PTEN) tumour suppressor gene on chromosome 10 and amplification of the epidermal growth factor receptor (EGFR) gene. ${ }^{14}$ The loss of chromosome 10 occurs in $60 \%$ to $85 \%$ of glioblastomas, with approximately $25 \%$ of cases having PTEN mutation. ${ }^{15}$ In approximately $40 \%$ of glioblastomas the EGFR gene is amplified, resulting in overexpression of EGFR. ${ }^{16}$

Glioblastomas can be classified as primary or de novo and secondary or progressive. Primary glioblastomas comprises the majority of cases $(60 \%)$, develop in older patients $(>50 \mathrm{y})$, without prior clinical history of less malignant tumours, presenting after the short medical history (less than 6 months). Secondary or progressive glioblastomas (40\%) are common among younger people $(<45 \mathrm{y})$ and arise through the progression from lower-grade astrocytomas (WHO grade II) or anaplastic astrocytomas (WHO grade III), with varying time for the progression, between less than 1 year to more than 10 years. Primary and secondary glioblastomas obviously constitute distinct disease entities that evolve through different genetic pathways. CDKN2A deletions, PTEN alterations and EGFR amplification are more prevalent among de novo glioblastomas and less frequently, mouse double minute 2 homolog (MDM2) amplification, whereas p53 mutations develop as earliest detectable alteration in secondary glioblastomas (Figure 1). ${ }^{17}$

\section{Prognostic factors}

Age, tumour grade (anaplastic gliomas versus glioblastoma) and performance status are three most 
TABLE 2. The chromosomal alterations, mostly observed in gliomas

\begin{tabular}{|c|c|c|}
\hline Chromosomal region & Type of alteration & Candidate gliomas genes \\
\hline 1p36.31-pter & Gains and deletions & Not known \\
\hline $1 p 36.22-p 36.31$ & Gains and deletions & Not known \\
\hline 1p34.2-p36.1 & Gains and deletions & Not known \\
\hline 1932 & Gains & $\begin{array}{l}\text { Receptor interacting protein kinase } 5 \text { (RIPK5), mouse double minute } 4 \\
\text { (MDM4), phosphatidylinositol-4-phosphate 3-kinase, catalytic subunit type } 2 \\
\text { beta (PIK3C2B) and others }\end{array}$ \\
\hline $4 q$ & Deletions & NIMA-related kinase 1 (NEK1), NIMA \\
\hline $7 p 11.2-p 12$ & $\begin{array}{l}\text { Amplifications or } \\
\text { gains }\end{array}$ & Epidermal growth factor receptor (EGFR) \\
\hline $9 p 21-p 24$ & Deletions & Cyclin-dependent kinase inhibitor 2A (CDKN2) \\
\hline $10 q 23$ & Deletions & Phosphatase and tensin homolog (PTEN) \\
\hline $10 q 25-q 26$ & Deletions & O-6-methylguanine-DNA methyltransferase (MGMT) \\
\hline $11 p$ & Deletions & $\begin{array}{l}\text { Between cyclin-dependent kinase inhibitor } 1 C \text { (CDKNIC) and related RAS } \\
\text { viral (r-ras) oncogene homolog } 2 \text { (RRAS2) }\end{array}$ \\
\hline $12 q 13.3-q 15$ & Amplifications & $\begin{array}{l}\text { Mouse double minute } 2 \text { homolog (MDM2), cyclin-dependent kinase } 4 \\
\text { (CDK4) and others }\end{array}$ \\
\hline $\begin{array}{l}13 p 11-p 13 \text { and } \\
13 q 14-q 34\end{array}$ & Loss & Retinoblastoma 1 (RB 1$)$ \\
\hline $19 q 13$ & Loss & $\begin{array}{l}\text { Glioma tumor suppressor candidate region gene 1 (GLTSCR1), GLTSCR2, } \\
\text { ligase I, DNA, ATP-dependent (LIG1), cytohesin } 2 \text { (CYTH2) and many others }\end{array}$ \\
\hline $22 q 11.21-q 12.2$ & Loss & 28 genes, including integrase interactor 1 (INII) \\
\hline $22 \mathrm{q} 13.1-\mathrm{q} 13.3$ & Loss & Not known \\
\hline
\end{tabular}

important prognostic factors affecting response to the treatment, along with extend of initial surgical resection. ${ }^{5,18,19}$ Lamborn et al. showed the aforementioned by study of 832 patients with glioblastoma in which the outcome was analysed by the recursive partitioning analysis. ${ }^{20}$

Also for patients with newly diagnosed glioblastoma, nomograms that incorporate patient age, extent of resection, use of postoperative (adjuvant) temozolomide, mental status and corticosteroid use as a baseline for prognostic factors, have been developed for estimation of the median survival and two year survival probability, as a helpful tool in decision making for individual patients. ${ }^{21}$ Nomograms have been developed on the bases of Stupp et al., temozolomide adjuvant trial from 2005.22

\section{Prognostic and predictive markers}

Oligodendrogliomas with $1 p / 19 q$ deletions have been recognized as distinct pathologic entities with particular sensitivity to RT and chemotherapy (ChT). In the retrospective analysis, the patients with tumours' epigenetic silencing of the methylguanine methyl transferase (MGMT) gene promoter by methylation benefited from temozolomide.
The tumours were unable to repair ChT induced DNA damage. ${ }^{23}$

IDH1 (NADP+-dependent isocitrate dehydrogenases) mutation occurs in the vast majority of WHO grade II or III gliomas and secondary glioblastomas. ${ }^{24}$ The p.Arg132His mutation (substitution of arginine with histidine) of isocitrate dehydrogenase 1 (IDH1 $1^{\mathrm{R} 132 \mathrm{H}}$ ) is not only a frequent alteration $(>70 \%$ ) but also a major prognostic marker in gliomas. ${ }^{25}$ Patients with IDH1 mutation have a better treatment outcome and a better survival. ${ }^{26}$

\section{Diagnosis}

\section{Clinical manifestations}

Clinical manifestations of malignant gliomas depend on the localization and size of the tumour. The variety of symptoms may be present, such as headaches and seizures (50-60\%), focal neurologic deficits, confusion, memory loss and personality changes $(20 \%){ }^{27}$

The classic headache suggestive of increased intracranial pressure is most severe in the morning and may be associated with nausea and vomitting. ${ }^{28}$

Rarely meningeal dissemination may be the first presentation of malignant gliomas as back pain 
TABLE 3. Symptoms at presentation of glioblastoma

\begin{tabular}{l}
\hline Headache \\
\hline Nausea/vomiting \\
Cognition changes \\
Personality changes \\
Gait imbalance \\
Urinary incontinence \\
Hemiparesis \\
Aphasia \\
Hemineglect \\
Visual field defect \\
Seizures
\end{tabular}

with or without radicular symptoms, mental status changes, cranial nerve palsies, and myelopathy or cauda equina syndrome (Table 3 ). ${ }^{29,30}$

\section{Imaging}

Diagnosis and staging are made by imaging of the brain and tumour hystopathologic verification. For imaging the magnetic resonance (MRI) is preferred, but computed tomography may also be used. Additional biopsy or tumour resection follows afterwards.

Imaging studies show heterogeneously enhancing mass with surrounding oedema. Glioblastomas frequently have central areas of necrosis and more extensive peritumoral oedema than in anaplastic gliomas. ${ }^{31}$

Tissue diagnosis is essential, it can be attended either at the time of surgical resection or by separate procedure named frameless stereotactic biopsy. In the case of frameless stereotactic biopsy, the neurosurgeon is aware of the three dimensional positions of surgical instruments inside the intracranial space during the biopsy, because it is MRI or CT guided. ${ }^{32}$ The procedure related mortality is $1-2 \%{ }^{33}$

Positron emission tomography (PET) ${ }^{34}$ and magnetic resonance spectroscopy (MRS) can be used to identify metabolically active areas of different tumours, and by that increasing the accuracy of stereotactic brain biopsy. PET can be integrated with the use of 18F-labeled fluorodeoxyglucose (FDGPET) or L-[methyl-(11) C]-methionine (MET-PET) increasing the diagnostic sensitivity and specificity. The both image procedures MET-PET and FDGPET correspond with each other. ${ }^{35}$

\section{Systemic treatment for malignant gliomas}

\section{Postoperative (adjuvant) therapy}

\section{Glioblastoma}

Because of their infiltrative nature, malignant gliomas cannot be completely eliminated with surgery. The standard treatment after surgery today for glioblastoma is concomitant RT-ChT with temozolomide (RT of 60 Gy and temozolomide $75 \mathrm{mg} / \mathrm{m}^{2} /$ day for 6 weeks), followed by the adjuvant temozolomide therapy $\left(150-200 \mathrm{mg} / \mathrm{m}^{2} /\right.$ day for 5 days every 28 days for 6 cycles). As reported by Stupp et al. ${ }^{22}$, this RT-ChT) combination has an acceptable side effect profile and as compared with RT alone (60 Gy for 6 weeks), increased the median survival (14.6 months vs. 12.1 months, $\mathrm{p}<0.001)$. The survival rate among the patients treated with RT/CTh was significantly higher than the rate among the patients that received RT alone at two and five years, respectively ( $26.5 \%$ vs. $10.4 \%$ and $10 \%$ vs. $2 \%$ ).

MGMT promoter methylation was a major prognostic factor for the improved survival and was predictive of benefit from the therapy. For those with MGMT methylation, the two years survival rates were $49 \%$ and $24 \%$ with combination therapy and RT alone respectively, while for those without MGMT methylation, the two year survival rates were $15 \%$ and $2 \%$ respectively.

The 5-year overall survival analysis of the European Organisation for Research and Treatment of Cancer (EORTC) and National Cancer Institute of Canada (NCIC) trial has shown benefit for patients treated with RT and temozolomide compared with only irradiated patients $(9.8 \%$ vs. $1.9 \%)$, the median survival after the progression remains only 6.2 months, regardless of the initial treatment. ${ }^{36}$

Adjuvant ChT with procarbazine, lomustine (CCNU) and vincristine (PCV regimen) has failed to improve the survival in individual prospective randomized studies, both in grade IV and in grade III tumours. One large meta-analysis has showed that nitrosourea based CTh marginally improves the survival. Namely, individual patient data from 3004 patients enrolled in 12 randomized controlled trials comparing RT alone or with CTh, were included, CTh was associated with a 15\% decrease in the risk of death, which translated to a $6 \%$ absolute increase in one year survival (from $40 \%$ to $46 \%$ ) and a two month improvement in the median survival. ${ }^{37}$

There are no randomized trials that have compared temozolomide with a nitrosourea-based 
TABLE 4. Summary of current treatments for malignant gliomas* (Adapted from ref.28)

\begin{tabular}{|c|c|}
\hline Type of Tumour & Therapy \\
\hline \multicolumn{2}{|l|}{ Newly diagnosed tumours } \\
\hline Glioblastoma (WHO grade IV) & Maximal surgical resection, plus radiotherapy, plus concomitant and adjuvant TMZ ** \\
\hline Anaplastic astrocytoma (WHO grade III) & $\begin{array}{l}\text { Maximal surgical resection, with the following options after surgery (no accepted standard } \\
\text { treatment): radiotherapy, plus concomitant and adjuvant TMZ or adjuvant TMZ alone** }\end{array}$ \\
\hline $\begin{array}{l}\text { Anaplastic oligodendroglioma and } \\
\text { anaplastic oligoastrocytoma (WHO grade III) }\end{array}$ & $\begin{array}{l}\text { Maximal surgical resection, with the following options after surgery (no accepted standard } \\
\text { treatment): radiotherapy alone, TMZ or PCV with or without radiotherapy afterward, } \\
\text { radiotherapy plus concomitant and adjuvant TMZ, or radiotherapy plus adjuvant } \mathrm{TMZ}^{*_{+}}\end{array}$ \\
\hline Recurrent tumours & $\begin{array}{l}\text { Reoperation in selected patients, conventional chemotherapy (e.g., lomustine, carmustine, PCV, } \\
\text { carboplatin, irinotecan, etoposide), bevacizumab plus irinotecan, experimental therapies + }\end{array}$ \\
\hline
\end{tabular}

* Additional data are from Sathornsumette et al. ${ }^{47}$, Furnari et al. ${ }^{48}$, Chi and Wen ${ }^{49}$ and Sathornsumetee et al. ${ }^{50}$; ${ }^{* *}$ Radiotherapy is administered at a dose of 60 Gy given in 30 fractions over a period of 6 weeks. ; Adjuvant TMZ = adjuvant temozolomide, beginning 4 weeks after radiotherapy, $150 \mathrm{mg} / \mathrm{m}^{2} / \mathrm{day}$ on days 1 to 5 of the first 28 -day cycle, followed by $200 \mathrm{mg} / \mathrm{m}^{2} /$ day on days 1 to 5 of each subsequent 28 -day cycle, if the first cycle was well tolerated; Concomitant TMz = concomitant temozolomide, $75 \mathrm{mg} / \mathrm{m}^{2} /$ day for 42 days with radiotherapy; PCV = lomustine (CCNU), $110 \mathrm{mg} / \mathrm{m}^{2}$, on day 1; procarbazine, $60 \mathrm{mg} / \mathrm{m}^{2}$ on days 8 to 21 ; vincristine, $1,5 \mathrm{mg} / \mathrm{m}^{2}$ (maximum dose, $2 \mathrm{mg}$ ), on days 8 and 29; WHO = World Health Organization

combination regimen when given concurrently with RT followed by the adjuvant therapy.

Another chemotherapeutic approach involves the implantation of biodegradable polymers containing carmustine (Gliadel Wafers, MGI Pharma) into the tumour bed after the resection of the tumour. The aim of the treatment with these polymers, which release carmustine gradually over the course of several weeks, is to kill residual tumour cells. In a randomized, placebo-controlled trial that investigated the use of these polymers in patients with newly diagnosed malignant gliomas, the median survival increased from 11.6 months to 13.9 months $(p=0.03) .{ }^{38}$ This survival advantage was maintained at 2 and 3 years. ${ }^{39}$

The newest phase III study data, in patients with newly diagnosed patients with glioblastoma, are coming from Radiation Therapy Oncology Group (RTOG) 0825 and Avastin in Glioblastoma (AVAGLIO) studies. In RTOG 0825 study, 637 newly diagnosed patients were randomly assigned to receive either standard ChT-RT (with temozolomide plus bevacizumab (10 $\mathrm{mg} / \mathrm{kg}$ intravenous [IV], q 2 weeks), or standard ChT-RT plus placebo). The progression-free survival was significantly improved in the bevacizumab arm: 10.7 months vs. 7.3 months for placebo. However, the overall survival was slightly (although not significantly) worse in the bevacizumab arm: 15.7 months vs. 16.1 months for placebo. In addition, patients in the bevacizum$\mathrm{ab}$ arm had a greater symptom burden and worse neurocognitive functioning, and they scored worse on several measures of health-related quality of life (QOL) than did patients who received only a standard therapy. ${ }^{40}$

The AVAGLIO trial, which had a study design very similar to that of RTOG 0825 and which in- volved 921 patients, also showed an improvement in progression-free survival (10.6 months in the bevacizumab arm vs. 6.2 months in the placebo arm) but virtually identical overall survival (16.8 months vs. 16.7 months, respectively). However, the QOL outcome in the bevacizumab arm was more favourable than in RTOG 0850 and time to the initiation of the corticosteroid treatment to manage adverse effects was also significantly longer in the patients who received bevacizumab (a median of 12.3 months vs. 3.7 months for placebo). ${ }^{41}$

\section{Anaplastic astrocytoma}

The standard therapy after surgery for anaplastic astrocytoma is still RT up to $60 \mathrm{~Gy}$ after the surgery. Currently, there are no findings from controlled trials that support the use of concurrent temozolomide in patients with anaplastic astrocytomas. ${ }^{42}$

\section{Anaplastic oligodendrogliomas and anaplastic oligoastrocytomas}

Anaplastic oligodendrogliomas and anaplastic oligoastrocytomas are generally more responsive to therapy than are pure astrocytic tumours. ${ }^{43}$ Nearly $90 \%$ of patients with anaplastic oligodendrogliomas and $20 \%$ patients with anaplastic oligoastrocytomas has a co-deletion of chromosomes $1 p$ and $19 q$, mediated by an unbalanced translocation of $19 p$ to $1 q .{ }^{44}$ Tumours in patients with the $\mathrm{LOH}$ $1 \mathrm{p} / 19 \mathrm{q}$ co-deletion are particularly sensitive to CTh with PCV with response rates of up to $100 \%$, as compared with response rates of 23 to $31 \%$ among patients without the deletion LOH of $1 \mathrm{p} / 19 \mathrm{q}$.

Two large phase III studies of PCV ChT with RT, as compared with RT alone, in patients with newly diagnosed anaplastic oligodendrogliomas or anaplastic oligoastrocytomas, have been reported. In 
both studies, the addition of ChT to RT increased the time to tumour progression by 10 to 12 months, but, did not improve the overall survival (median, 3.4 and 4.9 years). ${ }^{45,46}$ No difference in efficacy was apparent between PCV and temozolomide $\mathrm{CTh}^{43}$, however, studies directly comparing the two regimens have not been performed (Table 4).

\section{Pseudo progression}

In patients with malignant gliomas, treated with temozolomide and RT, have been described with sub-acute treatment-related reactions with or without clinical deterioration, showing oedema and sometimes contrast enhancement on MRI, suggestive of tumour progression. ${ }^{51-53}$ The occurrence of pseudo progression is mostly within the first 2 months after temozolomide ChT-RT.

In a prospective phase III trials with RT only, pseudo progression occurred in three of 32 (9\%) patients. ${ }^{54}$ More recent study on 85 patients with malignant gliomas treated with temozolomide ChT-RT, pseudo progression occurred in 18 (21\%) patients. ${ }^{55}$ In one third of patients treated with temozolomide ChT-RT, the increase in radiological abnormalities was accompanied by new focal signs, but in most patients the increase in radiological abnormalities was clinically asymptomatic. ${ }^{55}$ In the study involving 103 patients, pseudo progression was noted in 32 patients $(31 \%)$, and was clinically symptomatic in $11(34 \%)$ of these patients. Patients with MGMT have more frequent pseudo progression and it was connected with better overall survival. ${ }^{56}$

Most likely, pseudo progression is induced by a pronounced local tissue reaction with an inflammatory component, oedema, and abnormal vessel permeability causing new or increased contrast enhancement on neuroimaging. In less severe cases, this event can subside without the further treatment, but in more severe cases it can result, over time, in true treatment-related necrosis.

The possibilities of a good functional outcome in patients with malignant gliomas could be increased with good early medical rehabilitation treatment. ${ }^{57}$

\section{Treating the recurrent malignant gliomas}

For glioblastoma, median time to progression after the treatment with RT and temozolomide is 6.9 months. ${ }^{36}$ In case of symptomatic disease from mass effect, reoperation may be indicated (Table 4), with limited prolongation of survival afterwards. ${ }^{58}$

The treatment of recurrent malignant gliomas with RT is controversial. Some data have suggest- ed that fractionated stereotactic reirradiation (SRT) and stereotactic radiosurgery (SRS) may be beneficial. ${ }^{59}$ Observational series of patients with recurrent malignant gliomas, treated with SRT showed the median survival of 12 months for patients with grade III tumours and eight months for those with grade IV lesions. ${ }^{60}$ The one-year survival rates were $65 \%$ and $23 \%$ for patients with grade III and IV lesions, respectively. Kong DS et al. in patients with recurrent gliomas treated with SRS has achieved progression free survival for patients with grade III and grade IV of 8.6 and 4.6 months, respectively. ${ }^{61}$ All patients were treated with SRS treatments delivered by gamma knife, except for 5 patients treated by linear accelerator.

The conventional ChT is more effective for anaplastic gliomas than for glioblastomas. In general, the conventional ChT has modest value for recurrent malignant gliomas. There is no established ChT regimen available and patients are best treated within investigational clinical protocols. Temozolomide was evaluated in a phase II study in patients with recurrent anaplastic gliomas who had previously been treated with nitrosoureas. ${ }^{62}$ The response rate was 35\%, and the 6-month rate of progression-free survival was $46 \%$, comparing favourably with the $31 \%$ rate of progression-free survival at 6 months for therapies that were reported to be ineffective. ${ }^{63}$ In patients with recurrent glioblastomas, temozolomide has only limited activity, with response rate of $5.4 \%$ and 6 -month rate of progression-free survival of $21 \% .{ }^{64}$ Different temozolomide doses and administration regimens have been developed. With the aim of depleting MGMT, Brock et al..$^{65}$ conducted a phase I trial of continuous temozolomide administration, demonstrating that a dose of $75 \mathrm{mg} / \mathrm{m}^{2}$ daily up to 49 days is safe. Continuous dose-dense temozolomide administration at a dose of $100 \mathrm{mg} / \mathrm{m}^{2}$ for 3 weeks out of 4 or $150 \mathrm{mg} / \mathrm{m}^{2} 1$ week out of 2 will double the dose intensity and deplete peripheral blood mononuclear cells of MGMT. ${ }^{66,67}$ Continuous temozolomide administration is associated with profound lymphocytopenia and an increased risk for opportunistic infections. ${ }^{68,69}$

Other chemotherapeutic agents that are used for recurrent gliomas include nitrosoureas, carboplatin, procarbazine, irinotecan, and etoposide. Nitrosoureas (carmustine, fotemustine) either as single agents or in combination regimens as procarbazine, lomustine and vincristine (PCV) have shown activity in phase II studies in previously treated patients. Brandes et al. conducted a phase II study on 40 patients with recurrent glioblastoma 
following surgery and standard RT, treated with carmustine as monotherapy. Median time to progression was 13.3 weeks and progression-free survival at 6 months was $17.5 \%{ }^{70}$

As combination regiment PCV, Schmidt F et al., has applied to 86 patients with recurrent glioblastoma. There were three partial responses, but no complete responses. Median progression-free survival was 17.1 weeks and progression-free survival at 6 months was $38.4 \% .{ }^{71}$

Bevacizumab is a monoclonal antibody, which binds to vascular endothelial growth factor (VEGF), the key driver of neovascularization, and thereby inhibits the binding of VEGF to its receptors, VEGFR-1 and VEGFR-2, on the surface of endothelial cells. It demonstrated significant clinical activity in phase II studies using bevacizumab as a single agent or in combination with ChT agents such as irinotecan for patients with grade 3 and grade 4 malignant gliomas (higher objective response, progression-free survival and overall survival) in recurrent glioblastomas ${ }^{72-74}$ and has been approved by Food and Drug Administration (FDA) for the secondary treatment of glioblastoma in $\mathrm{USA}^{75}$, but it is not approved yet by European Medicines Agency (EMA). ${ }^{76}$

The most extensive experience with bevacizumab comes from a noncomparative phase II trial, in which 167 patients with recurrent glioblastomas, priory treated with ChT with temozolomide, were randomly assigned to bevacizumab, either as a single agent or at the same dose in conjunction with irinotecan. ${ }^{73}$ Treatment cycles were repeated every two weeks. The objective response rates with bevacizumab alone or in combination with irinotecan were $28 \%$ and $38 \%$, respectively, and the six-month progression-free survival rates and overall survival were $43 \%$ and $50 \%$, and 9.2 and 8.7 months, respectively. An update of the results was presented at the 2010 American Society of Clinical Oncology (ASCO) meeting. ${ }^{74}$ Overall safety and efficacy were similar to that previously presented; the 12 and 24 -month survival rates were $38 \%$ and $16 \%$ to $17 \%$ on both treatment arms, which appear to be better than historical control series.

According to our experience, at Institute of Oncology Ljubljana, we treated 19 patients with recurrent malignant gliomas with bevacizumab and irinotecan, from August 2008 to November 2011. The objective response rates were $47.4 \%$ and $10.5 \%$ after 3 and 6 months respectively. The sixmonth time to progression interval rate and overall survival were $52.6 \%$ and $68.4 \%$ and 6.8 and 7.7 months, respectively (Figure 1). ${ }^{77}$

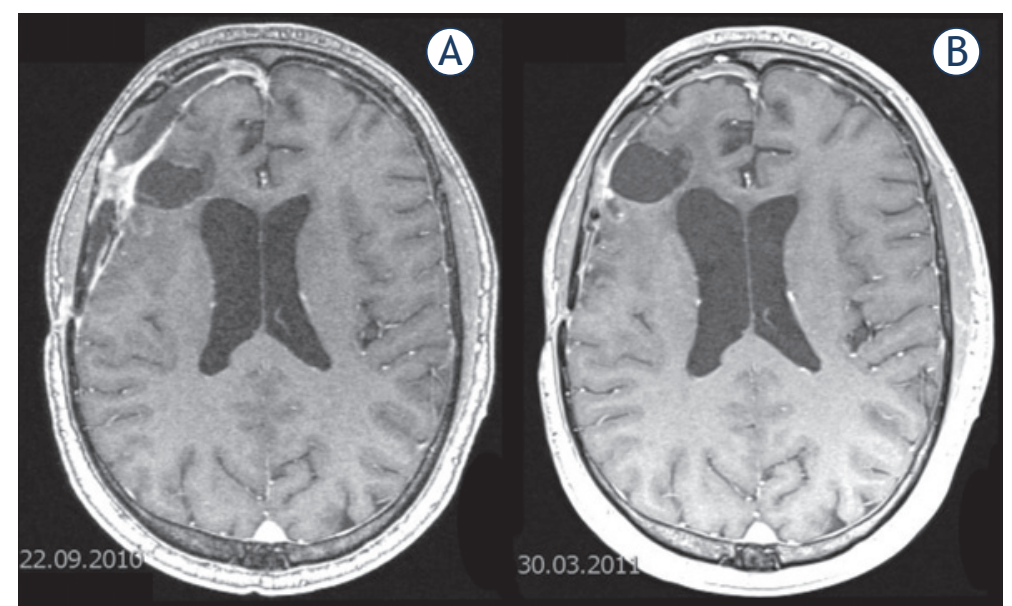

FIGURE 2. Magnetic resonance imaging (MRI) in recurrent glioblastoma patient, treated at Institute of Oncology Ljubljana, with bevacizumab/irinotecan, (A) before and (B) after six months of treatment.

Bevacizumab alone or in combination with ChT has not been demonstrated to prolong the overall survival. Pivotal studies to determine the impact of this agent on overall survival are ongoing.

\section{Treating the elderly}

According to the Central Brain Tumor Registry of United States of America (CBTRUS), in one series of over 14,000 cases, $44 \%$ of cases were patients aged 65 years or more. ${ }^{78}$ Older age and poor performance status are associated with shorter survival.

RT among patients older than 70 years has a modest benefit in the median survival (29.1 weeks) as compared with supportive care (16.9 weeks). ${ }^{79}$ Older patients tolerate therapy less well than younger patients, so the treatment regimen should be adjusted. RT applied as abbreviated course (40 Gy in 15 fractions over a period of 3 weeks) or temozolomide as monotherapy has similar outcomes as conventional RT regimens. ${ }^{80,81}$

Two contemporary randomized trials conducted exclusively in older patients have new data about the optimal treatment approach. Both trials, Methusalem trial (NOA-08) $)^{78}$ and Nordic Elderly Trial $^{82}$ have compared initial ChT as monotherapy with RT alone. In the Methusalem Trial the median age was 72 years. ${ }^{78}$ Patients treated with RT has a better survival, the median survival was 293 vs. 245 days, one year survival was $38 \%$ vs. $31 \%$, the toxicity was more severe in patients treated with CTh. In Nordic Elderly Trial the median age was 70 years. Patients were treated with RT 60 Gy (6 weeks), 34 Gy (6 weeks) and temozolomide as monothera- 
TABLE 5. Selected investigational therapies for malignant gliomas* (Adapted from ref. 28)

\begin{tabular}{|c|c|}
\hline Type of treatment & Example \\
\hline $\begin{array}{l}\text { Convection enhanced surgical } \\
\text { delivery of pharmacologic agent }\end{array}$ & Cintredekin besudotox \\
\hline \multicolumn{2}{|l|}{ Drugs to overcome resistance to TMZ } \\
\hline Dose dense TMZ & O'-benzylguanine \\
\hline MGMT inhibitors & BSI-201, ABT-888 \\
\hline PARP inhibitors & RTA 744, ANG 1005 \\
\hline \multicolumn{2}{|l|}{ New chemotherapies } \\
\hline \multicolumn{2}{|l|}{ Antiangiogenic therapies } \\
\hline Anti-avb5 integrins & Cilengitide \\
\hline Anti-hepatocyte growth factor & AMG-102 \\
\hline Anti-VEGF & Bevacizumab, aflibercept (VEGF-trap) \\
\hline Anti-VEGFR & $\begin{array}{l}\text { Cediranib, pazopanib, sorafenib, } \\
\text { sunitinib, vandetinib, vatalanib, XLI 84, } \\
\text { CT-322 }\end{array}$ \\
\hline Other agents & Thalidomide \\
\hline \multicolumn{2}{|l|}{ Targeted molecular therapies } \\
\hline Akt & Perifosine \\
\hline EGFR inhibitors & $\begin{array}{l}\text { Erlotinib, gefitinib, lapatinib, BIBW2992, } \\
\text { nimotuzumab, cetuximab }\end{array}$ \\
\hline FTI inhibitors & Tipifarnib, lonafanib \\
\hline HDAC inhibitors & Vorinostat, depsipeptide, LBH589 \\
\hline HSP90 inhibitors & ATI3387 \\
\hline Met & XLI84 \\
\hline mTOR inhibitors & $\begin{array}{l}\text { Everolimus, sirolimus, temsirolimus, } \\
\text { deforolimus }\end{array}$ \\
\hline PI3K inhibitors & BEZ235, XL765 \\
\hline $\mathrm{PKCb}$ & Enzastaurin \\
\hline PDGFR inhibitors & Dasatinib, imatinib, tandutinib \\
\hline Proteasome & Bortezomib \\
\hline Raf & Sorafenib \\
\hline Src & Dasatinib \\
\hline TGF-b & API2009 \\
\hline Combination therapies & $\begin{array}{l}\text { Erlotinib plus temsirolimus, gefitinib } \\
\text { plus everolimus, gefitinib plus sirolimus, } \\
\text { saorafenib plus temsirolimus, erlotinib, } \\
\text { or tipifarnib, pazopanib plus lapatinib }\end{array}$ \\
\hline \multicolumn{2}{|l|}{ Immunotherapies } \\
\hline $\begin{array}{l}\text { Dendritic cell and EGFRvIll peptide } \\
\text { vaccines }\end{array}$ & DCVax, CDX-110 \\
\hline Monoclonal antibodies & ${ }^{131}$ I-anti-tenascin antibody \\
\hline \multicolumn{2}{|l|}{ Gene therapy } \\
\hline Other therapies & ${ }^{131} \mid-T M-601$ \\
\hline
\end{tabular}

* Additional data are from Sathorsumetee et al. ${ }^{47}$, Furnari et al. ${ }^{48}$, Chi and Wen ${ }^{49}$, Sathornsumetee et $a . .^{50}$; EGFR = epidermal growth factor; FTI = farnesyltransferase; HDAC = histone deacetylase; HSP9O = heat-shock protein 90; MGMT = $0^{6}$-methylguanine-DNA methyltransferase; mTOR mammalian target of rapamycin; PARP = poly (ADP-ribose) polymerase; PDGFR = platelet-derived growth factor receptor; $\mathrm{PI} 3 \mathrm{~K}=$ phosphatidylinositol 3-kinase; $\mathrm{PKCb}=$ protein kinase $\mathrm{Cb}$; $\mathrm{TGF}=$ transforming growth factor; TMZ = temozolomide; VEGFR = vascular ednosthelial growth factor receptor; $\mathrm{WHO}=$ World Health Organization py. In this trial patients treated with CTh had a better survival, with the overall survival of $6,7.5$ and 8.3 months, respectively. It seems that there might be benefit from systemic treatment over RT in patients with MGMT methylated tumours.

\section{Experimental approaches}

Increased understanding of the molecular pathways involved in signal transduction, angiogenesis and cell growth has led to the development of a number of targeted agents, which are now under active evaluation, alone and in various combinations for patients with malignant gliomas and other tumours. Other investigational therapies for malignant gliomas include chemotherapeutic agents that cross the blood-tumour barrier more effectively, gene therapy, peptide and dendritic-cell vaccines, radiolabeled monoclonal antibodies against the extracellular matrix protein tenascin, synthetic chlorotoxins $\left({ }^{131} \mathrm{I}-\mathrm{TM}-601\right)$, and infusion of radiolabeled drugs and targeted toxins into the tumour and surrounding brain by means of convection-enhanced delivery. Promising investigational therapies are selected in Table $5 .{ }^{28}$

\section{Conclusions}

Malignant gliomas remains difficult to treat, and despite the efforts to improve the treatment outcome, the survival of patients with malignant gliomas is poor, with median survival of slightly above one year.

After revolutionary change in the postoperative setting with RT-ChT with Temozolomide has been achieved, mostly negative trials follow. AVAGLIO and RTOG 0825 trials were negative. Even though the AVAGLIO trial kind of suggests progressionfree survival and QOL improvement, these are not clear cut results and upon review the actual progression-free survival benefit was smaller, while QOL results are completely contradictory. In the recurrent malignant glioma setting, still nothing significant has been achieved.

The optimal management requires a multidisciplinary approach and knowledge of potential complications from both the disease and its treatment. In the future, with the better understanding of the molecular pathogenesis of malignant gliomas, it may be possible to select the most appropriate therapies on the basis of the patient's tumour genotype and in that way more effective therapies can be developed for malignant gliomas. Most of 
all, further targeted therapy approaches should be biomarker driven.

\section{References}

1. WHO Classification of tumours of the central nervous system. Louis DN, Ohgaki H, Wiestler OD, Cavenee WK, editors. Lyon: IARC Press; 2007.

2. CBTRUS, Central Brain Tumor Registry of the United States. 2007-2008. Primary brain tumors in the United States. Statistical report. 20002004 years of data collected. Available from: http://www.cbtrus.org/ reports/2007-2008/2007report.pdf. Accessed on 10 November 2013.

3. Kase M, Minajeva A, Niinepuu K, Kase S, Vardja M, Asser T, et al. Impact of CD133 positive stem cell proportion on survival in patients with glioblastoma multiforme. Radiol Oncol 2013; 47: 405-10.

4. Fisher JL, Schwartzbaum JA, Wrensch M, Wiemels JL. Epidemiology of brain tumors. Neurol Clin 2007; 25: 867-90.

5. Smrdel U, Kovac V, Popovic M, Zwitter M. Glioblastoma patients in Slovenia from 1997 to 2008. Radiol Oncol 2014; 48: 72-9.

6. Zakelj MP, Zadnik V, Zagar T, Zakotnik B. Survival of cancer patients, diagnosed in 1991-2005 in Slovenia. Ljubljana: Institute of Oncology Ljubljana, Epidemiology and Cancer Registry, Cancer Registry of Republic of Slovenia; 2009. p. 229.

7. Linos E, Raine T, Alonso A, Michaud D. Atopy and risk of brain tumours: a metaanalysis. J Natl Cancer Inst 2007; 99: 1544-50.

8. Wrensch M, Wiencke JK, Wiemels J, Miike R, Patoka J, Moghadassi M, et al. Serum IgE, tumour epidermal growth factor receptor expression and inherited polymorphisms associated with gliomas survival. Cancer Res 2006; 66: 4531-41.

9. Farell CJ, Plotkin SR. Genetic causes of brain tumors: neurofibromatosis, tuberous sclerosis, von Hippel-Lindau and other syndromes. Neurol Clin 2007; 25: 925-46.

10. Schwartzbaum JA, Fisher JL, Kenneth DA, Wrensch M. Epidemiology and molecular pathology of gliomas. Nature 2006; 2: 494-503.

11. Galli R, Binda E, Orfanelli U, Cipelletti B, Gritti A, De Vitis S, et al. Isolation and characterization of tumorigenic, stem-like neural precursors from human glioblastoma. Cancer Res 2004; 64: 7011-21.

12. Singh SK, Hawkins C, Clarke ID, Squire JA, Bayani J, Hide T, et al. Identification of human brain tumor initiating cells. Nature 2004; 432: 396-401.

13. Ueki K, Ono Y, Henson JW, Efird JT, von Deimling A, Louis DN. CDKN2A (p16) or RB alterations occur in majority of glioblastomas and are inversely correlated. Cancer Res 1996; 56: 150-3.

14. Fujisawa $\mathrm{H}$, Kurrer $\mathrm{M}$, Reis RM, Yonekawa Y, Kleihues $\mathrm{P}$, Ohgaki H. Acquisition of the glioblatoma phenotype during astrocytoma progression is associated with loss of heterozygocity on 10q25-qter. Am J Pathol 1999; 155: 387-94.

15. Li J, Yen C, Liaw D, Podsypanina K, Bose S, Wang SI, et al. PTEN, a putative protein tyrosine phosphatase gene mutated in human brain, breast, and prostate cancer. Science 1997; 275: 1943-7.

16. Watanabe K, Tachibana O, Sata K, Yonekawa $Y$, Kleihues $P$, Ohgaki H. Overexpression of the EGFR receptor and p53 mutations are mutually exclusive in the evolution of primary and secondary glioblastomas. Brain Pathol 1996; 6: 217-23.

17. Kleihues $\mathrm{P}$, Ohgaki $\mathrm{H}$. Primary and secondary globlastomas: from concept to clinical diagnosis. Neuro Oncol 1999; 1: 44-51.

18. Devaux BC, O'Fallon JR, Kelly PJ. Resection, biopsy, and survival in malignant glial neoplasms. A retrospective study of clinical parameters, therapy and outcome. J Neurosurg 1993; 78: 767-75

19. Laws ER, Parney IF, Huang W, Anderson F, Morris AM, Asher A, et al. Survival following surgery and prognostic factors for recently diagnosed malignant gliomas: data from the Glioma Outcomes Project. J Neurosurg 2003; 99: 467-73.

20. Lamborn KR, Chang SM, Prados MD. Prognostic factors for survival of patients with glioblastoma: recursive partitioning analysis. Neuro Oncol 2004; 6: 227-35
21. Gorlia T, van den Bent MJ, Hegi ME, Mirimanoff RO, Weller M, Cairncross JG, et al. Nomograms for predicting survival of patients with newly diagnosed glioblastoma: prognostic factor analysis of EORTC and NCIC trial 2698122981/CE.3. Lancet Oncol 2008; 9: 29-38.

22. Stupp R, Mason WP, van den Bent MJ, Weller M, Fisher B, Taphoorn MJB, et al. Radiotherapy plus concomitant and adjuvant temozolomide for glioblastoma. N Engl J Med 2005; 352: 987-96.

23. Hegi ME, Diserens AC, Gorlia T, Hamou MF, de Tribolet N, Weller M, et al. MGMT gene silencing and benefit from temozolomide in glioblastoma. $N$ Engl J Med 2005; 352: 997-1003.

24. Yan H, Parsons DW, Jin G, McLendon R, Rasheed BA, Yuan W, et al. IDH1 and IDH2 Mutations in Gliomas. N Engl J Med 2009; 360: 765-73.

25. Boisselier $B$, Marie $Y$, Labussière $M$, Ciccarino $P$, Desestret $V$, Wang $X$, et al. COLD PCR HRM: a highly sensitive detection method for IDH1 mutations. Hum Mutat 2010; 31: 1360-5.

26. Labussiere M, Sanson M, Idbaih A, Delattre JY. IDH1 gene mutations: a new paradigm in glioma prognosis and therapy? Oncologist 2010; 15: 196-9.

27. Chang SM, Parney IF, Huang W, Anderson FA Jr, Asher AL, Bernstein M, et al. Patterns of care for adults with newly diagnosed malignant gliomas. JAMA 2005; 293: 557-64.

28. Wen Py, Kesari S. Malignant gliomas in adults. N Engl J Med 2008; 359: 492-507.

29. Wheen LC, Anderson NE, Baker PC, Singh VK, Synek BJ. Leptomeningeal infiltration as the presenting manifestation of a malignant gliomas. J Clin Neurosci 2006; 13: 298-301.

30. Omuro A, DeAngelis LM. Glioblastoma and other malignant gliomas: a clinical review. JAMA 2013; 310: 1842-50.

31. Cha S. Update on brain tumour imaging: from anatomy to phisiology. AJNR Am J Neuroradiol 2006; 27: 475-87.

32. Paleologogs TS, Dorward NL, Wadley JP, Thomas DG. Clinical validation of true frameless stereotactic biopsy: analysis of the first 125 consecutive cases. Neurosurgery 2001; 49: 835-7.

33. Bernays RL, Kollias SS, Khan N, Brandner S, Meier S, Yonekawa Y. Histological yield, complications and technological considerations in 114 consecutive frameless stereotactic biopsy procedures aided by open intraoperative magnetic resonance imageing. J Neurosurg 2002; 97: 354-62.

34. Maza S, Buchert R, Brenner W, Munz DL, Thiel E, Korfel A, et al. Brain and whole-body FDG-PET in diagnosis, treatment monitoring and long-term follow-up of primary CNS lymphoma. Radiol Oncol 2013; 47: 103-10.

35. Pirotte B, Goldman S, Massager N, David P, Wikler D, Vandesteene A, et al Comparison of 18F-FDG and 11C-methionine for PET-guided stereotactic brain biopsy of gliomas. J Nucl Med 2004; 45: 1293-8.

36. Stupp R, Hegi EM, Mason PW, van den Bent MJ, Taphoorn JBM, Janzer CR, et al. Effects of radiotherapy with concomitant and adjuvant temozolomide versus radiotherapy alone on survival in glioblastoma in a randomised phase III study: 5-year analysis of the EORTC-NCIC trial. Lancet Oncol 2009; 10: 459-66.

37. Stewart LA. Chemotherapy in adult high-grade gliomas: a systematic review and meta-analysis of individual patient data from 12 randomised trials. Lancet 2002; 359: 1011-8.

38. Westphal M, Hilt DC, Bortey E, Delavault P, Olivares R, Warnke PC, et al. A phase 3 trial of local chemotherapy with biodegradable carmustine (BCNU) wafers (Gliadel wafers) in patients with primary malignant gliomas. Neuro Oncol 2003; 5: 79-88.

39. Westphal M, Ram Z, Riddle V, Hilt D, Bortey E. Gliadel wafer in initial surgery for malignant gliomas: long-term follow-up of a multicenter controlled trial. Acta Neurochir (Wien) 2006; 148: 269-75.

40. Gilbert MR, Dignam J, Won M, Blumenthal DT, Vogelbaum MA, Aldape KD, et al. RTOG 0825: phase III double-blind placebo-controlled trial evaluating bevacizumab (Bev) in patients (Pts) with newly diagnosed glioblastoma (GBM). [Abstract]. 2013 ASCO Annual Meeting. J Clin Oncol 2013; 31(18 Suppl): Abstract No. 1

41. Henriksson R, Bottomley A, Mason W, Saran F, Wick W, Nishikawa R, et al. Progression-free survival (PFS) and health-related quality of life (HRQoL) in AVAglio, a phase III study of bevacizumab (Bv), temozolomide (T), and radiotherapy (RT) in newly diagnosed glioblastoma (GBM). [Abstract]. 2013 ASCO Annual Meeting. J Clin Oncol 2013; 31(18 Suppl): Abstract No. 2005. 
42. Brem SS, Bierman PJ, Brem H, Butowski N, Chamberlain MC, Chiocca EA et al. Central nervous system cancers. J Natl Compr Canc Netw 2011; 9 352-400.

43. van den Bent MJ. Anaplastic oligodendroglioma and oligoastrocytoma. Neurol Clin 2007; 25: 1089-109.

44. Jenkins RB, Blair H, Ballman KV, Giannini C, Arusell RM, Law M, et al. A $t(1 ; 19)(q 10 ; p 10)$ mediates the combined deletions of $1 p$ and $19 q$ and predicts a better prognosis of patients with oligodendroglioma. Cancer Res 2006; 66: 9852-61.

45. Intergroup Radiation Therapy Oncology Group Trial 9402, Cairncross G, Berkey B, Shaw E, Jenkins R, Scheithauer B, et al. Phase III trial of chemotherapy plus radiotherapy compared with radiotherapy alone for pure and mixed anaplastic oligodendroglioma: Intergroup Radiation Therapy Oncology Group Trial 9402. J Clin Oncol 2006; 24: 2707-14.

46. van den Bent MJ, Carpentier AF, Brandes AA, Sanson M, Taphoorn $\mathrm{MJ}$, Bernsen $\mathrm{HJ}$, et al. Adjuvant procarbazine, lomustine, and vincristine improves progression-free survival but not overall survival in newly diagnosed anaplastic oligodendrogliomas and oligoastrocytomas: a randomized European Organisation for Research and Treatment of Cancer phase III trial. J Clin Oncol 2006; 24: 2715-22.

47. Sathorsumetee S, Rich JN, Reardon DA. Diagnosis and treatment of high grade astrocytoma. Neurol Clin 2007; 25: 1111-39.

48. Furnari FB, Fenton T, Bachoo RM, Mukasa A, Stommel JM, Stegh A, et al. Malignant astrocytic glioma: genetics, biology, and paths to treatment. Genes Dev 2007; 21: 2683-710.

49. Chi AS, Wen PY. Inhibiting kinases in malignant gliomas. Expert Opin Ther Targets 2007; 11: 473-96.

50. Sathorsumetee S, Reardon DA, Desjardins A, Quinn JA, Vredenburgh Jנ, Rich JN. Molecularly targeted therapy for malignant gliomas. Cancer 2007 110: $13-24$.

51. Fiegler W, Langer M, Scheer M, Kazner E. [Reversible computed tomographic changes following brain tumour irradiation induced by the "early-delayed reaction" after radiation]. [German]. Radiologe 1986; 26: 206-9.

52. Watne K, Hager B, Heier M, Hirschberg H. Reversible oedema and necrosis after irradiation of the brain. Diagnostic procedures and clinical manifestations. Acta Oncol 1990; 29: 891-5.

53. Griebel M, Friedman HS, Halperin EC, Wiener MD, Marks L, Oakes WJ, et al. Reversible neurotoxicity following hyperfractionated radiation therapy of brain stem gliomas. Med Pediatr Oncol 1991; 19: 182-6.

54. de Wit MC, de Bruin HG, Eijkenboom W, Sillevis Smitt PA, van den Bent MJ. Immediate post-radiotherapy changes in malignant gliomas can mimic tumour progression. Neurology 2004; 63: 535-7.

55. Taal W, Brandsma D, de Bruin HG, Bromberg JE, Swaak-Kragten AT, Smitt PA et al. The incidence of pseudoprogression in a cohort of malignant gliomas patients treated with chemo-radiation with temozolomide. [Abstract]. Proc Am Soc Clin Oncol 2007; 25: Abstract No. 2009.

56. Brandes AA, Franceschi E, Tosoni A, Blatt V, Pession A, Tallini G, et al. MGMT promoter methylation status can predict the incidence and outcome of pseudoprogression after concomitant radiochemotherapy in newly diagnosed glioblastoma patients. J Clin Oncol 2008; 26: 2192-7.

57. Kos N, Kos B, Benedicic M. Early medical rehabilitation after neurosurgica treatment of malignant brain tumours in Slovenia. Radiol Oncol 2015; 49: in press.

58. Keles GE, Lamborn KR, Chang SM, Prados MD, Berger MS, Volume of re sidual disease as a predictor of outcome in adult patients with recurrent supratentorial glioblastomas multiforme who are undergoing chemotherapy. J Neurosurg 2004; 100: 41-6.

59. Tsao MN, Mehta MP, Whelan TJ, Morris DE, Hayman JA, Flickinger JC, et al. The American Society for Therapeutic Radiology and Oncology (ASTRO) evidence-based review of the role of radiosurgery for malignant gliomas. Int I Radiat Oncol Biol Phys 2005; 63: 47-55.

60. Combs SE, Thilmann C, Edler L, Debus J, Schulz-Ertner D. Efficacy of fractionated stereotactic reirradiation in recurrent gliomas: long-term results in 172 patients treated in a single institution. J Clin Oncol 2005; 23: 8863-9.

61. Kong DS, Lee JI, Park K, Kim JH, Lim DH, Nam DH. Efficacy of stereotactic radiosurgery as a salvage treatment for recurrent malignant gliomas. Cancer 2008; 112: 2046-51.
62. Prados MD, Yung WKA, Fine HA, Greenberg HS, Junck L, Chang SM, et al. Phase 2 study of BCNU and temozolomide for recurrent glioblastoma multiforme: North American Brain Tumor Consortium study. Neuro Oncol 2004; 6: 33-7.

63. Wong ET, Hess KR, Gleason MJ, Jaeckle KA, Kyritsis AP, Prados MD, et al. Outcomes and prognostic factors in recurrent gliomas patients enrolled onto phase II clinical trials. J Clin Oncol 1999; 17: 2572-8.

64. Yung WK, Albright RE, Olson J, Fredericks R, Fink K, Prados MD, et al. A phase II study of temozolomide vs. procarbazine in patients with glioblastoma multiforme at first relapse. Br J Cancer 2000; 83: 588-93.

65. Brock CS, Newlands ES, Wedge SR, Bower M, Evans H, Colquhoun I, et al Phase I trial of temozolomide using an extended continuous oral schedule. Cancer Res 1998; 58: 4363-7.

66. Tolcher AW, Gerson SL, Denis L, Geyer C, Hammond LA, Patnaik A, et al. Marked inactivation of O6-alkylguanine-DNA alkyltransferase activity with protracted temozolomide schedules. Br J Cancer 2003; 88: 1004-11.

67. Wick W, Steinbach JP, Kuker WM, Dichgans J, Bamberg M, Weller M. One week on/one week off: a novel active regimen of temozolomide for recurrent glioblastoma. Neurology 2004; 62: 2113-5.

68. Su YB, Sohn S, Krown SE, Livingston PO, Wolchok JD, Quinn C, et al. Selective CD4+ lymphopenia in melanoma patients treated with temozolomide: a toxicity with therapeutic implications. J Clin Oncol 2004; 22: 610-6.

69. Wick W, Weller M. How lymphotoxic is dose-intensified temozolomide? The glioblastoma experience. J Clin Oncol 2005; 23: 4235-6; author reply 4236.

70. Brandes AA, Tosoni A, Amistà P, Nicolardi L, Grosso D, Berti F, et al. How effective is BCNU in recurrent glioblastoma in the modern era? A phase II trial. Neurology 2004; 63: 1281-4.

71. Schmidt F, Fischer J, Herrlinger U, Dietz K, Dichgans J, Weller M. PCV chemotherapy for recurrent glioblastoma. Neurology 2006; 66: 587-9.

72. KreisI TN, Kim L, Moore K, Duic P, Royce C, Stroud I, et al. Phase II trial of single-agent bevacizumab followed by bevacizumab plus irinotecan at tumor progression in recurrent glioblastoma. J Clin Oncol 2009; 27: 740-5.

73. Friedman HS, Prados MD, Wen PY, Mikkelsen T, Schiff D, Abrey LE, et al. Bevacizumab alone and in combination with irinotecan in recurrent glioblastoma. J Clin Oncol 2009; 27: 4733-40.

74. Cloughesy T, Vredenburgh JJ, Day B, Das A, Friedman HS. Updated safety and survival of patients with relapsed glioblastoma treated with bevacizumab in the BRAIN study. [Abstract]. J Clin Oncol 2010; 28(15 Suppl): Abstract No. 3085.

75. NCCN clinical practical guidelines in oncology. Central nervous system cancer. Version 2.2013. Available from: http://www.nccn.org/professionals/ physician_gls/f_guidelines.asp\#site. Accessed on 7 August 2012.

76. Stupp R, Tonn JC, Brada M, Pentheroudakis G. High grade malignant glioma: ESMO clinical practice guidelines for diagnosis, treatment and follow-up. Ann Oncol 2010; 21(Suppl 5): v190-3.

77. Mesti T, Ebert Moltara M, Boc M, Reberšek M, Ocvirk J. Bevacizumab and irinotecan in recurrent malignant glioma, a single institution experience. Radiol Oncol 2014. Ahead of print. doi:10.2478/raon-2014-0021

78. Wick W, Engel C, Combs SE, Nikkhah G, Steinbach J, Kortmann R, et al. NOA08 randomized phase III trial of 1 week on/ 1 week off temozolomide versus involved-field radiotherapy in elderly (older than age 65) patients with newly diagnosed anaplastic astrocytoma or glioblastoma (Methusalem). [Abstract]. J Clin Oncol 2010; 28: 949s. Abstract No. LBA2001.

79. Keime-Guibert F, Chinot O, Taillandier L, Cartalat-Carel S, Frenay M, Kanto $\mathrm{G}$, et al. Radiotherapy for glioblastoma in the elderly. N Engl J Med 2007; 356: 1527-35

80. Roa W, Brasher PM, Bauman G, Anthes M, Bruera E, Chan A, et al Abbreviated course of radiation therapy in older patients with glioblastoma multiforme: a prospective randomized clinical trial. J Clin Oncol 2004; 22 1583-8.

81. Glantz M, Chamberlain M, Liu Q, Litofsky NS, Recht LD. Temozolomide as an alternative to irradiation for elderly patients with newly diagnosed malignant gliomas. Cancer 2003; 97: 2262-6.

82. Malmstrom A, Gronberg BH, Stupp R, Marosi C, Frappaz D, Schultz HP, et al. Glioblastoma (GBM) in elderly patients: a randomized phase III tria comparing survival in patients treated with 6-week radiotherapy (RT) versus hypofractionated RT over 2 weeks versus temozolomide single agent chemotherapy (TMZ) for glioblastoma (GBM) in the elderly. [Abstract]. J Clin Oncol 2010; 28(18 Suppl): 949s. Abstract No. LBA2002 